ISSN 2075-4450

www.mdpi.com/journal/insects/

Article

\title{
Screening of Repellents against Vespid Wasps
}

\section{Jean-Luc Boevé $^{1, *}$, Kris Honraet ${ }^{2}$ and Bart Rossel ${ }^{2}$}

1 Service Entomology, Royal Belgian Institute of Natural Sciences, Rue Vautier 29, Brussels B-1000, Belgium

2 Oystershell Laboratories, Booiebos 24, Drongen B-9031, Belgium;

E-Mails: r\&d@oystershell.com (K.H.); bart.rossel@Oystershell.com (B.R.)

* Author to whom correspondence should be addressed; E-Mail: jean-luc.boeve@naturalsciences.be; Tel.: +32-2-6274-305; Fax: +32-2-6274-132.

Received: 28 November 2013; in revised form: 14 January 2014 / Accepted: 24 February 2014 / Published: 6 March 2014

\begin{abstract}
Vespid wasps are ecologically beneficial, but they can be a nuisance and dangerous to people due to their tendency to sting. Here, the aim was to screen samples of volatiles (i.e., essential oils and pure chemicals) for their repellency against wasps. The number of wasps (mainly Vespula vulgaris) present in a glass box with attractant and $5 \mu \mathrm{L}$ sample was compared to the number of wasps in a similar box with attractant only. Both boxes were connected to a large glass container harboring 18-35 wasps. Among 66 tested samples, some essential oils from Lamiaceae and Asteraceae, as well as some pure natural compounds such as the monoterpenes (-)-terpinen-4-ol and isopulegol showed a significant repellency against vespids. Our results corroborate the potential of (mixtures of) volatiles in repelling these insects.
\end{abstract}

Keywords: Vespidae; Vespula; repellent; volatiles; essential oils; Mentha; laboratory testing

\section{Introduction}

Wasps of the family Vespidae (Hymenoptera) can sting in order to attack and in defense, and their painful stings constitute a hazard to humans and other vertebrates [1-4]. People are exposed to this risk during their professional and recreational outdoor activities, and stings are a real medical concern since some people can die from anaphylactic shock [5,6]. Consequently, methods to monitor and control wasp populations have been developed that are based on fumigation and removal of nests, on trapping 
in combination with poisoned baits [7-15], or on the use of natural enemies such as pathogenic agents [16]. Generally, these methods may be considered as either too destructive, for instance, when the whole wasp nest is destroyed, not effective because wasp colonies can recover [17], or not sufficiently selective since non-pest insects are killed in traps as well [18]. Thus, there is still a need for other controlling methods.

Several Vespidae species live in colonies and are commonly foraging in various natural, agricultural, and urban areas such as forests, orchards, public parks, and private gardens [19]. Notwithstanding their status as a pest, wasps play an important ecological role and they are a major predator of many flies, defoliating caterpillars, etc. [20]. They offer perhaps intangible, but substantial "management services" in controlling (other) pest insects but when present as an invasive species, wasps may disturb food webs [21-24], especially when considering their interactions with honeybees [13,25-28]. Approximately 20 Vespinae and Polistinae species occur in Europe, but only some of them are considered pests: Vespula vulgaris (Linnaeus, 1758), Vespula germanica (Fabricius, 1793), Vespa crabro Linnaeus, 1758, Polistes dominulus (Christ, 1791), and the recently invading Vespa velutina Lepeletier, 1836 [29,30]. Ideally, a management program devoted to the control of pestiferous wasps should be adapted to also maintain the biodiversity and the generally beneficial effects of wasps.

The present work was aimed at the screening of wasp repellents to point out the most promising ones, and to this effect we designed a laboratory bioassay. In a recent paper, Zhang et al. [31] demonstrated the potential of volatiles as repellents against wasps. These authors identified several essential oils and pure chemicals by combining field trappings and physiological experiments using electroantennogram detection (EAD). We present a laboratory bioassay by which large batches of samples of volatiles can be studied quite conveniently for their potential repellency against wasps.

Volatiles are known to play important roles in the chemical communication of vespid species. They function intra-specifically as alarm [5,32-35], marking [36] and queen [37] pheromones, while cuticular lipids are implicated in nestmate recognition [38,39] and they include trail pheromones [40,41] and probably sex pheromones [42,43]. Nest-based cues also enable wasps to exploit food resources [44] and volatile acts between species, for instance, when wasps are attracted to plant odors $[45,46]$ by olfactory learning [47]. Moreover, prey pheromones can have a kairomonal effect on wasps, such as a 1:1 mixture of linalool or $\alpha$-terpineol and (E)-2-hexenal that attracts Vespula maculifrons $[48,49]$. However, such wasp communication systems mediated by volatiles are dose-dependent. For instance, venom constituents such as acetals can attract but also alarm or even repel wasps depending on their concentration [50,51].

Here, we designed an in vitro bioassay to gradually select samples of volatiles for their repellency on wasp workers. A few active samples were tested after diluting and mixing them in an attempt to infer general trends of the bioactivity of volatiles on wasps. Our findings are discussed from a practical point of view as well as placed in a chemo-ecological context. 


\section{Materials and Methods}

\subsection{Collection of Wasps, and Samples}

Vespid wasps were collected in the field using a net during the periods August-September 2011 and July-August 2012 (Table 1) at daytime, generally in the morning. For transport to the laboratory, the wasps were individually placed in plastic vials (diameter $3.5 \mathrm{~cm}$, height $7 \mathrm{~cm}$ ) and they were provided with a droplet of grenadine syrup. Relatively few wasps could be collected due to bad weather conditions during these two years, forcing us to group individuals from 1-3 species, although each group generally included one major species (Table 1).

Table 1. Collection data and numbers of collected wasp species, Vespula vulgaris (V.v.), Vespula germanica (V.g.), and Polistes dominula (P.d.), used in this study. ${ }^{a}$ Date(s) of collection. ${ }^{\mathrm{b}}$ The four localities mentioned are situated in Belgium. ${ }^{\mathrm{c}}$ Numbers in parentheses correspond to males. ${ }^{\mathrm{d}}$ Unidentifiable specimens.

\begin{tabular}{|c|c|c|c|c|c|c|c|}
\hline Group & Date $(d / m / y)^{a}$ & Locality $^{\text {b }}$ & Remark & V.v. & V.g. & P.d. ${ }^{\mathrm{c}}$ & $\mathbf{U S}^{\mathbf{d}}$ \\
\hline 01 & $10 / 08 / 2011$ & Vlezenbeek & In and around a garbage container & 16 & 29 & & \\
\hline 02 & $16-17 / 08 / 2011$ & Vlezenbeek & As Group 01 & 6 & 30 & & \\
\hline 03 & $23 / 08 / 2011$ & Vlezenbeek & As Group 01 & 2 & 30 & $1(+1)$ & \\
\hline 04 & $31 / 08 / 2011$ & Ortho & From a nest at the base of a spruce trunk & 32 & & & 2 \\
\hline 05 & $10-12 / 09 / 2011$ & Vlezenbeek and Uccle & $\begin{array}{l}\text { As Group 01, and from wasp traps placed } \\
\text { in a garden }\end{array}$ & 6 & 3 & $\begin{array}{c}10 \\
(+3)\end{array}$ & \\
\hline 06 & $16-18 / 07 / 2012$ & Vlezenbeek & From a nest at the base of a concrete wall & 49 & & & \\
\hline 07 & $24-26 / 07 / 2012$ & Vlezenbeek & As Group 06 & 37 & & & \\
\hline 08 & $31 / 07-02 / 08 / 2012$ & Vlezenbeek and Uccle & $\begin{array}{c}\text { As Group 06, and from wasp traps placed } \\
\text { in a garden }\end{array}$ & 26 & & & \\
\hline 09 & $04-12 / 08 / 2012$ & Vlezenbeek and Uccle & As Group 08 & 21 & 1 & 2 & 1 \\
\hline 10 & $14 / 08 / 2012$ & Geraardsbergen & From trash cans in a park & 26 & 4 & & \\
\hline 11 & $20 / 08 / 2012$ & Geraardsbergen & As Group 10 & 31 & 7 & & \\
\hline 12 & $27 / 08 / 2012$ & Geraardsbergen & As Group 10 & 40 & 2 & & \\
\hline
\end{tabular}

Samples of essential oils and pure compounds were obtained from the following companies. Essential oils (possible synonym, plant family): Juglans regia (Juglandaceae) (Croda, Nettetal, Germany); Rose Turkish (Rosa damascena, Rosaceae) (Danisco, Brugge, Belgium); Artemisia absinthium (wormwood), Artemisia herba-alba (Asteraceae), Mentha spicata (Lamiaceae) and Zingiber officinalis (Zingiberaceae) (Essencia Ätherische Öle, Winterthur, Switzerland); Melaleuca alternifolia (Myrtaceae) (Kreglinger Europe, Antwerpen, Belgium); Chamaemelum nobile (Asteraceae), Gaultheria procumbens (Ericaceae), Juniperus virginiana (Cupressaceae), Laurus nobilis (Lauraceae), Melaleuca alternifolia (Myrtaceae), Mentha arvensis, Nepeta cataria, Origanum majorana (Lamiaceae), Pinus sylvestris (Pinaceae) and Valeriana officinalis (Valerianaceae) (Pranarôm International, Ghislenghien, Belgium); Hippophae (sea buckthorn, Elaeagnaceae) (Safic-Alcan, Londerzeel, Belgium); Lavendula angustifolia (Lamiaceae) (Sensient Essential Oils, Bremen, Germany); Caryophyllus aromaticus (Myrtaceae), Cymbopogon nardus (Poaceae) and Helichrysum italicum (Asteraceae) (Sjankara, Tielt, Belgium); and Rosae aetheroleum (Rosaceae) (Synaco, Knokke-Heist, Belgium). 
Mixtures not as essential oils: pyrethrum extract (Chrysanthemum, Asteraceae, 0.05\% w/w in isododecane) (Kenya Pyrethrum Information Centre, Kuchl, Austria); pitch-oil (Pohjolan Terva, Kursu, Finland); Carnation ${ }^{\circledR}$ (Sonnneborn, Amsterdam, The Netherlands); and sunflower oil (Helianthus annuus, Asteraceae) (Vandemoortele, Izegem, Belgium).

Pure chemicals (synonym, purity as far as known, possible solid phase): 7(Z)-pentacosene (Bio-Connect, Huissen, The Netherlands); isopropyl alcohol (Conforma, Destelbergen, Belgium); Frescolat $^{\circledR}$ MGA and Frescolat ${ }^{\circledR}$ ML (crystals) (Cosnaderm, Amsterdam, The Netherlands); 3-methylpentacosane (solid) and 7-ethyl-2-methyl-1,6-dioxaspiro(4,5)decane (Ecosynth, Oostende, Belgium); lilial and alpha-irone (Essencia Ätherische Öle, Winterthur, Switzerland); $N$-(3-methylbutyl)acetamide (Frinton Laboratories, Hainesport, NJ, USA); menthyl PCA (Questice ${ }^{\circledR}$, $25 \%$ in ethanol) (GOVA, Antwerpen, Belgium); isododecane and isoeicosane (IMCD, Wormermeer, The Netherlands); diisopropyl adipate (Ceraphyl ${ }^{\circledR}$ 230) (Keyser \& Mackay, Bruxelles, Belgium); propylene glycol (Mosselman, Ghlin, Belgium); ethyllactate (Purac, Gorinchem, The Netherlands); saltidin (picaridin, icaridin) (Saltigo, Einsiedeln, Switzerland); (-)-terpinen-4-ol, 2-heptanone, 2-nonanone (99\%), benzaldehyde, camphor (96\%, solid), carvone, eucalyptol (99\%), eugenol (99\%), heptyl butyrate (98\%), isopulegol, linalool, menthol (solid), menthone, methyl anthranilate, methyl salicylate, myrcene (85\%), $N$-ethyl-2-isopropyl-5-methylcyclohexane, octanoic acid, oleic acid, thymol (99.5\%), (+)-cis-p-menthane-3,8-diol, and triethyl citrate (98\%) (Sigma-Aldrich, Diegem, Belgium); DEET (Vertellus, Antwerpen, Belgium); IR3535 (VWR International, Haasrode, Belgium).

\subsection{Experimental Setup}

A glass container (width $60 \mathrm{~cm}$, depth $40 \mathrm{~cm}$, height $40 \mathrm{~cm}$ ) was composed of fixed walls and floor, and a removable lid (Figure 1A). It had five holes. Three holes were located on the front wall: two low, left and right, and one small high and centered. The back wall had two larger holes which were covered by a stainless steel grid. A removable glass box $(8 \times 8 \times 10 \mathrm{~cm})$ could be attached to the container in front of each of the two lower front holes with the open side facing the container (Figure 1B). A removable glass plate (width $10 \mathrm{~cm}$, height $15 \mathrm{~cm}$ ) could then be used as a sliding door between the container and the box. A cold light source was directed via two gooseneck arms from above on each one of these boxes. The three walls (left, right and behind) and the top of the container were protected from light with white cardboard covers so that the only light allowed came from the front of the container (Figure 1A). A ventilator was used by removing the cardboard from the back wall and directing the airflow into the container through the lower grid covered hole. Note that by doing so, the airflow venting from the higher grid-covered hole could clearly be detected.

\subsection{Bioassay}

At least 18 wasps from one group were transferred into the glass container via the central, front hole that was otherwise closed with a rubber plug (Figure 1A). The number of wasps in the container varied during the period of testing (i.e., maximum one week; see later). More wasps could be added, sometimes to replace dead or moribund ones. The latter, if possible, were taken out of the container and kept in ethanol for later identification (Table 1). Wasps were also added to compensate an overall activity decrease in the container. During the night the wasps were provided with grenadine syrup and water. 
Figure 1. Annotated photography of the bioassay set-up. (A) Overviewing picture showing the glass container and, among others, two boxes on the left and right sides; note that the glass reflects the light coming from a window. (B) One of the two boxes ready for testing a sample on the wasps; this picture represents the left box, thus with the container on the right side of the picture.

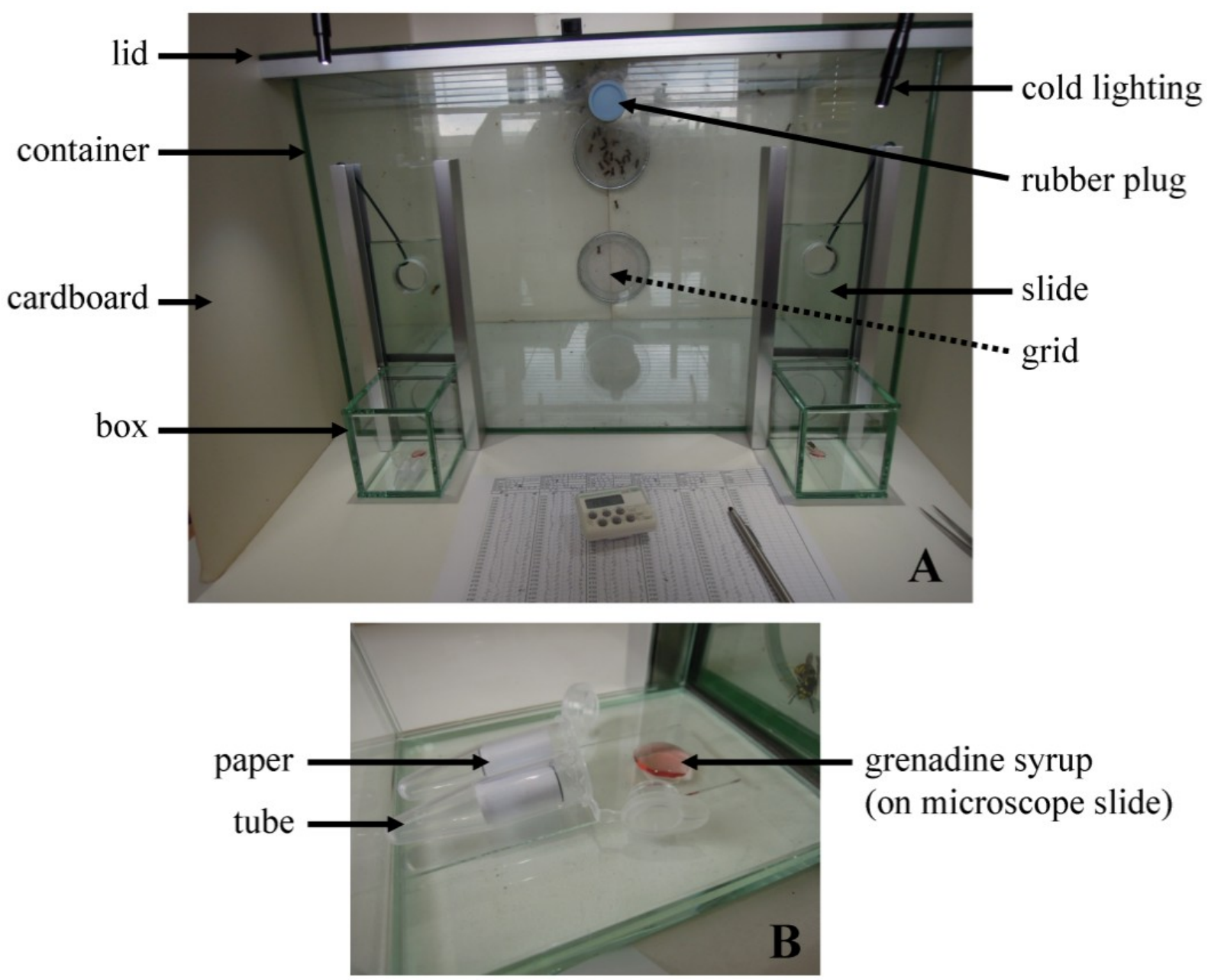

In order to test the samples, a $1.5 \times 3.0 \mathrm{~cm}$ piece of paper (Dolphin Premium, $80 \mathrm{~g} \mathrm{~m}^{-2}$; Dolphin Papers, Franklin, IN, USA) was rolled and placed into a plastic Eppendorf tube (vol. $1.5 \mathrm{~mL}$ ). For each experiment, two plastic tubes were weighed together (i.e., tare weight). Then, in each tube $2.5 \mu \mathrm{L}$ of the sample were deposited on the paper, preliminary tests showing that in this way the evaporation (of $5 \mu \mathrm{L}$ ) was enhanced. The two tubes were then immediately closed and weighed again together (start weight). In each glass box, a microscope glass slide was placed, and $200 \mu \mathrm{L}$ of grenadine syrup (i.e., attractant) was deposited on one end of the slide. Then, the two tubes were opened and placed in one of the two glass boxes, on the slide (see positioning in Figure 1B). The box with the tubes was fixed at random on the left or right side of the container. Both boxes were attached to the container and the sample was allowed to evaporate inside the box for $2 \mathrm{~min}$. Afterwards, the glass plates were drawn and held upwards (see Figure 1A) so that the wasps could get into the boxes. The time point of opening was set as $t=0$. The number of wasps in each box was then counted and recorded every $10 \mathrm{~s}$, from $t=10 \mathrm{~s}$ to $\mathrm{t}=5 \mathrm{~min}$ (i.e., 30 matched pairs of counts; first run). Prior to closing off the boxes with the removable slides, we made sure all the wasps had withdrawn back into the main container. 
This could take a few minutes and wasps could be coaxed back by using a light source directed from the backside of the container. Then, the boxes were removed from the container, the two tubes taken out, closed and weighed together (intermediate weight). The container was ventilated for at least $1 \mathrm{~min}$ and the two boxes were ventilated for at least $5 \mathrm{~min}$. On rare occasions, if more than $50 \%$ of the sample had already evaporated, an additional $2 \times 2.5 \mu \mathrm{L}$ of sample were added to the paper in the tubes that were then weighed again (after this extra load). The tubes were placed again in one of the two boxes, the right box if the sample was first tested on the left side, and vice versa. The same test was then performed in a second run after which the two tubes were weighed for a last time (final weight). The temperature inside the container was recorded. After an "experiment" (i.e., two successive runs), the two tubes were discarded, and the microscope slides were cleaned. The succession of samples used in the experiments was determined at random. Wasps were used during 2-7 days, after which they were killed, kept in ethanol for identification (see Table 1), and replaced by new ones, collected in the field.

\subsection{Screening of Volatiles}

The samples were mainly chosen in an exploratory way by including common essential oils and a series of pure chemicals. Some were chosen because they reportedly modulate behavioral processes of vespids (e.g., [34,35,39]), others because they are mentioned in the EU Biocidal Product Directive, or because they have a known insecticidal activity.

Each sample was used in at least two experiments. It was then selected for retesting if it showed a significant repellent activity with the Sign test in both experiments (see later).

\subsection{Dilutions and Mixtures of Selected Samples}

From the screening process, four of the most active samples were chosen for further analysis. The samples were diluted in propylene glycol $(10 \%, 17.8 \%, 31.5 \%$, and $56.2 \%)$ and the repellency of the dilutions was determined with the bioassay. The repellency of the six possible combinations of two by two mixtures (vol. 1:1) of the same samples was determined as well. The experiments were performed in triplicate (i.e., six runs per dilution or mixture).

\subsection{Statistics and Calculations}

For each experiment, the double (from two runs) series of 30 matched pairs of wasp numbers were averaged per min and rounded to the nearest integer, and these 10 pairs of values were used in the non-parametric Sign test [52]. The Sign test offered the advantage to be applicable per experiment, thus allowing a daily statistical check of which samples were to be tested further.

However, drawbacks of the Sign test in this setup are the temporal auto-correlation of the data since successive numbers of wasps could (partly) correspond to the same wasp individuals and since not (all) the same wasps were participating in the two runs. Therefore, the overall screening dataset was analyzed with $\mathrm{R}$ version 2.15.3 and from which the following values were extracted. The performance of the experiment itself was determined at the control side by the total time without wasps (TTWW) and the maximum number of wasps (MNW). Note that a low TTWW and high MNW are desirable 
since this reflects frequent wasp visits and a high number of wasps visiting, meaning high wasp participation. A repellent potency was also computed based on a weighted score taking into account the 30 time points for each of the (test and control) sides, and assigning more weight to the absence of wasps (as for the TTWW). This score was set equal to: $\left(\mathrm{N}_{0} \times 4\right)+\left(\mathrm{N}_{1}\right)+\left(\mathrm{N}_{2} \times 0.5\right)+\left(\mathrm{N}_{3} \times 0.25\right)+$ $\left(\mathrm{N}_{>3} \times 0.1\right)$, where $\mathrm{N}_{\mathrm{y}}$ is the number of time points with $\mathrm{y}$ wasps. The repellent potency was the difference between the scores of the test and control side. Since the expected minimum and maximum scores were 3 and 120 the repellent potency could vary from -117 to 117 , the latter denoting the highest possible repellent potency.

From each experiment the evaporation rate (in \%) of the sample was calculated with the formula: [(final weight - start weight) $/($ final weight - tare weight $)] \times 100$. The rate was adjusted in those cases where the samples needed to be replenished.

\section{Results}

\subsection{Repellency of Screened Samples}

From 208 screening experiments performed in 2011 and 2012 on a total of 66 samples, only a minority were statistically significant in the Sign test. Hence, most samples were tested not more than three times. The repellent potency of all tested samples (Figure 2) revealed that the 10 most (consistent) repellent samples were the essential oils of G. procumbens, O. majorana, Artemisia spp., and M. arvensis, as well as the chemicals menthone, linalool, (-)-terpinen-4-ol, isopulegol, and methyl salicylate. Strikingly, the "repellents" of the PT19 class of the annex II of the BPD, such as DEET, IR3535, saltidin, and (+)-cis-p-menthan-3,8-diol, showed (almost) no repellent potency against wasps (Figure 2).

\subsection{Repellency and Evaporation Rates}

During the experiments, the temperature in the container ranged from $22-32{ }^{\circ} \mathrm{C}$ and the evaporation rate of the samples ranged from 0-96\%. In eight experiments, the sample was reapplied to the paper in the tubes before performing the second run of the experiment, and in these cases, $49 \%-92 \%$ of the sample evaporated during the two runs of the experiment. Considering all samples, a high repellent potency $(>30)$ was associated with a low evaporation rate $(\leq 20 \%)$ (Figure 3$)$.

\subsection{Repellency of Dilutions and Mixtures}

The most consistent repellent samples tested during 2011 were two mint oils, M. spicata and $M$. arvensis, and the two chemicals isopulegol and (-)-terpinen-4-ol. These four samples were chosen during 2012 to be tested as dilutions and mixtures. The samples were generally less active once diluted, but a dose-dependent decrease in activity was clear only for M. spicata (Table 2). Further, mixing these four samples two by two in all six possible combinations never resulted in an increase of repellent potency (Table 3). 
Figure 2. Samples screened for their repellent potency against wasps. Dot plot (left diagram) and box-and-whisker plot (right diagram) of the repellent potencies. Samples are ordered according to a decreasing median of the repellent potency. Each dot in the dot plot represents the repellent potency calculated from one run.

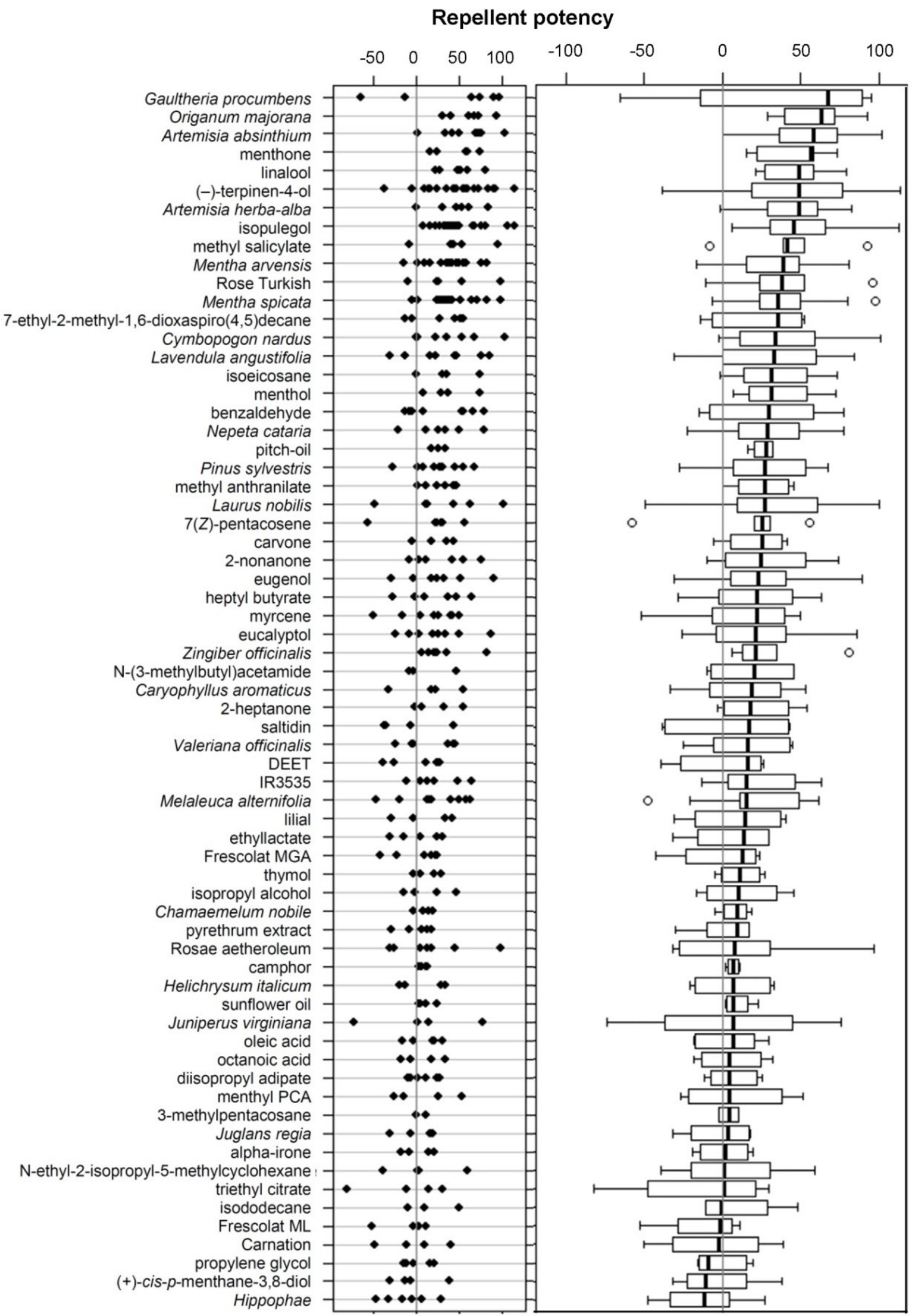


Figure 3. Distribution of the samples as a function of their repellent potency against wasps and their evaporation rate.

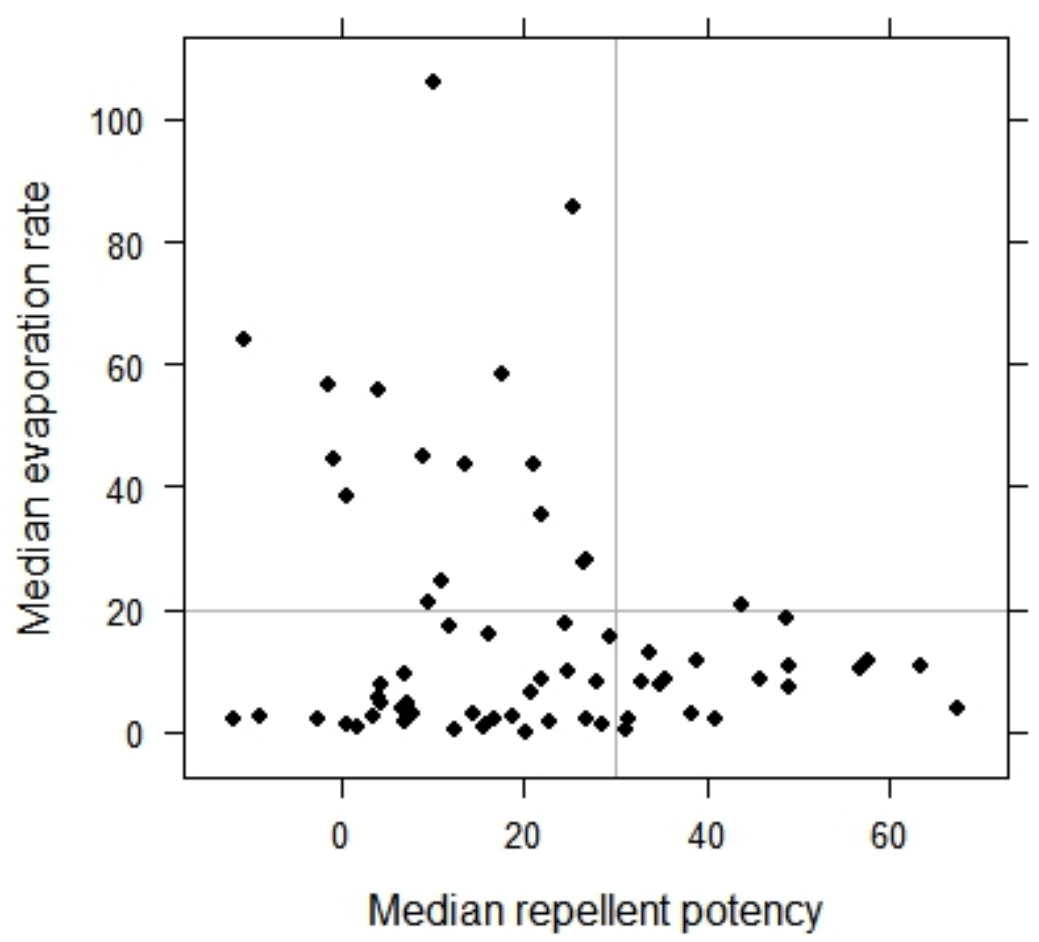

Table 2. Repellent potency of four samples as a function of their concentration. Values given as repellent potency (mean $\pm \mathrm{SD}$ ). Values in square brackets are the number of runs performed. ${ }^{\mathrm{b}}$ Log values of the sample diluted in propylene glycol.

\begin{tabular}{cccccc}
\hline Essential oils and & \multicolumn{5}{c}{ Concentration $^{\mathbf{b}}$} \\
\cline { 2 - 6 } pure chemicals & $\mathbf{0 . 0 0}$ & $\mathbf{- 0 . 2 5}$ & $\mathbf{- 0 . 5 0}$ & $\mathbf{- 0 . 7 5}$ & $\mathbf{- 1 . 0 0}$ \\
\hline Mentha spicata & $38.3 \pm 27.3$ & $28.3 \pm 25.0$ & $24.1 \pm 17.7$ & $21.8 \pm 27.4$ & $-7.6 \pm 19.1$ \\
& {$[18]$} & {$[6]$} & {$[6]$} & {$[6]$} & {$[6]$} \\
Mentha arvensis & $36.3 \pm 24.9$ & $8.7 \pm 14.1$ & $0.3 \pm 9.6$ & $1.7 \pm 13.1$ & $2.3 \pm 8.5$ \\
& {$[18]$} & {$[8]$} & {$[6]$} & {$[6]$} & {$[6]$} \\
$(-)$-terpinen-4-ol & $47.4 \pm 37.7$ & $18.0 \pm 19.3$ & $28.4 \pm 34.2$ & $7.0 \pm 13.2$ & $8.5 \pm 38.0$ \\
& {$[20]$} & {$[6]$} & {$[8]$} & {$[6]$} & {$[6]$} \\
isopulegol & $49.9 \pm 28.9$ & $10.0 \pm 36.1$ & $15.5 \pm 9.3$ & $25.2 \pm 14.4$ & $-5.3 \pm 48.2$ \\
& {$[18]$} & {$[6]$} & {$[6]$} & {$[6]$} & {$[6]$} \\
\hline
\end{tabular}

Table 3. Repellent potency of four samples tested by mixing them two by two. All mixtures in volume 1:1. Values are given as repellent potency (mean $\pm \mathrm{SD}$ ) above the names of the essential oils and pure chemicals, whereas values in square brackets and below these names are the number of runs performed.

\begin{tabular}{cccc}
\hline Mentha spicata & $20.0 \pm 34.1$ & $15.7 \pm 17.8$ & $16.4 \pm 21.9$ \\
{$[6]$} & Mentha arvensis & $8.2 \pm 34.0$ & $36.4 \pm 23.4$ \\
{$[6]$} & {$[6]$} & $(-)$-terpinen-4-ol & $-2.3 \pm 7.0$ \\
{$[6]$} & {$[6]$} & {$[6]$} & isopulegol \\
\hline
\end{tabular}




\subsection{Bioassay Assessment}

Besides the repellence itself of the samples, we detected four factors which potentially influenced the results. First, not all wasps participated equally in the experiment, with wasps of groups 3, 4 and 10-12 participating the most (Table 4). Second, each group was characterized by a predominant wasp species (see Table 1): V. germanica for groups 1-3, V. vulgaris for groups 4 and 6-12, and $P$. dominula for group 5. The lowest TTWW and highest MNW were obtained with $V$. vulgaris as compared to the two other species (Table 5). Third, a side preference was often observed, that is wasps tended to frequent the right box slightly more than the left box (TTWW $=26.2 \pm 44.0 \mathrm{~s}$ for right against $42.8 \pm 52.3 \mathrm{~s}$ for left). This may lead to overestimating the repellent potency of samples on the left side. Fourth, after a couple of days, wasps tended to become immobile and stayed in a cluster on the grids (as shown in Figure 1A), or at the underside of the container's glass lid.

Table 4. Statistical values as a function of the 12 groups of wasps. ${ }^{\text {a }}$ Total time without wasps (sec). ${ }^{b}$ Maximum number of wasps.

\begin{tabular}{|c|c|c|c|c|c|c|c|}
\hline \multirow{2}{*}{ Group } & \multirow{2}{*}{ Runs $(N)$} & \multicolumn{2}{|c|}{ Mean \pm SD } & \multicolumn{2}{|c|}{ Median } & \multicolumn{2}{|c|}{ Min-Max } \\
\hline & & TTWW $^{\text {a }}$ & MNW $^{b}$ & TTWW $^{\text {a }}$ & MNW $^{\text {b }}$ & TTWW $^{\mathrm{a}}$ & MNW $^{b}$ \\
\hline 01 & 56 & $52.1 \pm 56.0$ & $4.2 \pm 1.8$ & 30 & 4 & $0-210$ & $1-9$ \\
\hline 02 & 54 & $65.4 \pm 70.6$ & $4.5 \pm 2.4$ & 45 & 4 & $0-250$ & $2-12$ \\
\hline 03 & 32 & $21.3 \pm 38.8$ & $6.0 \pm 2.4$ & 0 & 6 & $0-130$ & $2-12$ \\
\hline 04 & 50 & $23.6 \pm 36.4$ & $5.5 \pm 1.9$ & 10 & 5 & $0-200$ & $2-9$ \\
\hline 05 & 16 & $45.6 \pm 45.2$ & $3.6 \pm 1.3$ & 30 & 4 & 10-190 & $2-7$ \\
\hline 06 & 20 & $37.0 \pm 49.2$ & $5.1 \pm 2.3$ & 20 & 4 & $0-170$ & $1-9$ \\
\hline 07 & 46 & $38.7 \pm 43.0$ & $4.4 \pm 1.7$ & 20 & 4 & $0-160$ & $2-9$ \\
\hline 08 & 56 & $44.1 \pm 70.0$ & $4.8 \pm 1.9$ & 15 & 5 & $0-300$ & $0-10$ \\
\hline 09 & 22 & $59.1 \pm 58.1$ & $3.4 \pm 1.3$ & 45 & 3 & $0-220$ & $1-6$ \\
\hline 10 & 64 & $15.2 \pm 17.8$ & $6.4 \pm 1.8$ & 10 & 6 & $0-70$ & $3-10$ \\
\hline 11 & 76 & $17.0 \pm 22.2$ & $6.3 \pm 2.0$ & 10 & 6 & $0-110$ & $3-13$ \\
\hline 12 & 66 & $25.0 \pm 34.4$ & $6.1 \pm 2.0$ & 10 & 6 & $0-150$ & $2-12$ \\
\hline
\end{tabular}

Table 5. Statistical values as a function of the predominant wasp species in the groups.

${ }^{\mathrm{a}}$ Total time without wasps (sec). ${ }^{\mathrm{b}}$ Maximum number of wasps.

\begin{tabular}{ccccccccc}
\hline \multirow{2}{*}{ Wasp species } & \multirow{2}{*}{ Runs $(\boldsymbol{N})$} & \multicolumn{2}{c}{ Mean \pm SD } & \multicolumn{2}{c}{ Median } & \multicolumn{2}{c}{ Min-Max } \\
\cline { 3 - 8 } & & TTWW $^{\mathbf{a}}$ & $\mathbf{M N W}^{\mathbf{b}}$ & TTWW $^{\mathbf{a}}$ & $\mathbf{M N W}^{\mathbf{b}}$ & TTWW $^{\mathbf{a}}$ & $\mathbf{M N W}^{\mathbf{b}}$ \\
\hline Vespula vulgaris & 400 & $28.5 \pm 42.8$ & $5.5 \pm 2.1$ & 10 & 5 & $0-300$ & $0-13$ \\
Vespula germanica & 142 & $50.2 \pm 60.9$ & $4.7 \pm 2.3$ & 30 & 4 & $0-250$ & $1-12$ \\
Polistes dominula & 16 & $45.6 \pm 45.2$ & $3.6 \pm 1.3$ & 30 & 3.5 & $10-190$ & $2-7$ \\
\hline
\end{tabular}

\section{Discussion}

The present study evidences that both essential oils and pure chemicals can act as repellents, but a majority of the 66 tested samples were not repellent in each run. This may be partly explained by the fact that the amount of $5(=2 \times 2.5) \mu \mathrm{L}$ sample was rather low. A 1:1 mixture of $(-)$-terpinen-4-ol and isopulegol was tested in three experiments by using $10(=2 \times 5) \mu \mathrm{L}$ and it showed each time a 
significant repellency (i.e., $p \leq 0.004$ three times; Sign test, two-tailed). From $5 \mu \mathrm{L}$, however, the repellent potency decreased rapidly upon dilution of such chemicals. Thus, the $5 \mu \mathrm{L}$ used in the screening assay is a quite low amount. Since samples were also less active once mixed, it seems that they have neither a synergistic, nor an additive repellent activity.

The four aforementioned factors that may have influenced our experimental results were also counteracted by the bioassay setup itself, as follows: the succession of testing samples was randomized within and among the groups of wasps; test and control sides were always switched between the left and right boxes (i.e., the first and second run within each experiment); when the wasp activity decreased over time, fresh wasps were released in the container. Several negative controls were performed by testing unloaded instead of loaded vials, and they always led to non-significant results (data not shown). Further, different vespid species were often tested simultaneously, but they are known to react similarly towards repellents [31], and aggressive interactions were rarely observed in the container and boxes.

Some essential oils and their respective major constituents both exhibited a high repellent potency. This was the case, for instance, for G. procumbens and methyl salicylate, or M. arvensis and menthol ([53]; Figure 2). The latter compound is a characteristic constituent of the essential oil of peppermint (Mentha spp.), and five of its analogues were tested. Surprisingly, these (six) substances were strongly dissimilar in their repellency against wasps. Only menthone was in the same range of activity as menthol (Figure 2), hinting that their common part, 5-methyl-2-isopropylhexane, contributes importantly to this bioactivity.

Volatiles can have opposite effects on vespids depending on their concentration and on the context in which they are emitted and perceived. For instance, spiroacetals are constituents of the venom and alarm conspecifics, while they have been used as wasp attractants [35,51]. Wasps are attracted to green-leaf volatiles [48,49] and it is assumed that such compounds indirectly indicate the feeding activity of phytophagous insects that constitute potential prey. They are also attracted to plant odors indicating a source of carbohydrates [47]. For instance, leaves of catmint, N. cataria, can become highly attractive to wasps through a sugar rewarding [47], while the essential oil of this plant was found to be a moderate or weak repellent (Figure 2), and its major compound, nepetalactone, as a strong or moderate repellent [31]. Such dissimilar behavioral responses are not inconsistent with EAD responses of wasps (see [31]), because chemicals can trigger an antennal reaction, regardless of being a repellent, or attractant. The general physiological state of the wasps should also be considered. Wasps tested in the present study were provided with grenadine syrup, which progressively decreased their satiation level (especially if compared to wasps in nature). We did not consider learning or habituation processes towards neither grenadine syrup that is a fruit blend, nor the chemicals/samples themselves, and both aspects would require further testing.

\section{Conclusions}

Converting experimental results into an applied solution to combat the hazard of vespids remains a challenging task. On the one hand, the use of volatiles should be promoted, regarding, generally, the ecological importance of vespids in limiting the impact of other pest insects. The aforementioned remarks on the chemical ecology of wasps lead, however, to the general conclusion that numerous aspects 
will affect the final effectiveness of a commercial product, depending also on the application strategy. One option is the "repel and attract (i.e., push-pull) strategy" where wasps are kept away from people as well as attracted to poisoned traps [54]. However, just a "repel strategy" would not only be ecologically more relevant, but also sufficient when people spend time outdoors. On the other hand, the application of strongly scented essential oils may be offensive to repellent users so that it is important to carefully select the least offensive repellents. The present study reveals essential oils and pure chemicals as effective repellents, and some of these may be especially promising in that their level of perception by humans can be low. One should also put in balance agricultural and/or industrial processes, economic costs, and the environmental impact for each type of chemicals, to optimize the formulation of volatiles so that humans can protect themselves, in a sustainable way, against the hazard of pestiferous wasps.

\section{Acknowledgments}

We thank Nico Lenaerts from Rentokil ${ }^{\circledR}$ for informing about convenient sampling stations, the beer company Lindemans and the provincial domain De Gavers where Jean-Luc Boevé was allowed to collect wasps, Jean-Luc Renneson for identifying the wasps, Els Adriaens for performing the R analyses, Frederik Hendrickx for discussing statistical issues, and three anonymous reviewers.

\section{Author Contributions}

The study was conceived by Bart Rossel and Jean-Luc Boevé. Kris Honraet managed the chemical samples. The bioassay setup was designed by Kris Honraet and Jean-Luc Boevé. Jean-Luc Boevé performed field collections and laboratory experiments, and wrote main parts of the manuscript. Data analyses were supervised by Kris Honraet and Jean-Luc Boevé. All authors read and approved the manuscript.

\section{Conflicts of Interest}

Jean-Luc Boevé received funding under a Research \& Development contract from Oystershell Laboratories, and he was free and independent in the analysis and interpretation of the bioassay results as well as in writing the manuscript.

\section{References}

1. Akre, R.D.; Davis, H.G. Biology and pest status of venomous wasps. Annu. Rev. Entomol. 1978, 23, 215-238.

2. Schmidt, J.O. Hymenopteran venoms: Striving toward the ultimate defense against vertebrates. In Insect Defenses: Adaptive Mechanisms and Strategies of Prey and Predators; State University of New York Press: Albany, NY, USA, 1990; pp. 387-419.

3. Pasquet, A.; Cardot, J.; Leborgne, R. Wasp attacks and spider defence in the orb weaving species Zygiella x-notata. J. Insect Behav. 2007, 20, 553-564.

4. De Haro, L.; Labadie, M.; Chanseau, P.; Cabot, C.; Blanc-Brisset, I.; Penouil, F. Medical consequences of the Asian black hornet (Vespa velutina) invasion in Southwestern France. Toxicon 2010, 55, 650-652. 
5. Ono, M.; Terabe, H.; Hori, H.; Sasaki, M. Components of giant hornet alarm pheromone. Nature 2003, 424, 637-638.

6. Krishna, M.T.; Ewan, P.W.; Diwakar, L.; Durham, S.R.; Frew, A.J.; Leech, S.C.; Nasser, S.M. Diagnosis and management of hymenoptera venom allergy: British Society for Allergy and Clinical Immunology (BSACI) guidelines. Clin. Exp. Allergy 2011, 41, 1201-1220.

7. Spurr, E.B.; Drew, K.W.; Read, P.E.C.; Elliott, G. The effectiveness of a sulfluramid concentrate mixed with canned sardine cat-food for control of wasps. In Proceedings of the 49th New Zealand Plant Protection Conference, Nelson, New Zealand, 13-15 August 1996; pp. 132-136.

8. Spurr, E.B. Freeze-dried bait for wasp control. In Proceedings of the 50th New Zealand Plant Protection Conference, Lincoln, New Zealand, 18-21 August 1997; pp. 401-404.

9. Landolt, P.J.; Reed, H.C.; Aldrich, J.R.; Antonelli, A.L.; Dickey, C. Social wasps (Hymenoptera: Vespidae) trapped with acetic acid and isobutanol. Fla. Entomol. 1999, 82, 609-614.

10. Landolt, P.J.; Smithhisler, C.S.; Reed, H.C.; McDonough, L.M. Trapping social wasps (Hymenoptera: Vespidae) with acetic acid and saturated short chain alcohols. J. Econ. Entomol. 2000, 93, 1613-1618.

11. Landolt, P.J.; Tóth, M.; Jósvai, J. First European report of social wasps trapped in response to acetic acid, isobutanol, 2-methyl-2-propanol and heptyl butyrate in tests conducted in Hungary. Bull. Insectol. 2007, 60, 7-11.

12. Makino, S.; Sayama, K. Species compositions of vespine wasps collected with bait traps in recreation forests in northern and central Japan (Insecta, Hymenoptera, Vespidae). Bull. FFPRI 2005, 4, 283-289.

13. Bacandritsos, N.; Papanastasiou, I.; Saitanis, C.; Roinioti, E. Three non-toxic insect traps useful in trapping wasps enemies of honey bees. Bull. Insectol. 2006, 59, 135-145.

14. Reierson, D.A.; Rust, M.K.; Vetter, R.S. Traps and protein bait to suppress populations of yellowjackets (Hymenoptera: Vespidae). In Proceedings of the Sixth International Conference on Urban Pests, Veszprém, Hungary, 13-16 July 2008; Robinson, W.H., Bajomi, D., Eds.; pp. 267-274.

15. Rust, M.K.; Reierson, D.A.; Vetter, R. Developing Baits for the Control of Yellowjackets in California; Department of Entomology, University of California: Riverside, CA, USA, 2010; pp. 1-33.

16. Merino, L.; France, A.; Gerding, M. Selection of native fungi strains pathogenic to Vespula germanica (Hymenoptera: Vespidae). Agric. Técnica 2007, 67, 335-342.

17. Toft, R.J.; Harris, R.J. Can trapping control Asian paper wasp (Polistes chinensis antennalis) populations? N. Z. J. Ecol. 2004, 28, 279-282.

18. Spurr, E.B. Carbohydrate bait preferences of wasps (Vespula vulgaris and $V$. germanica) (Hymenoptera: Vespidae) in New Zealand. N. Z. J. Zool. 1996, 23, 315-324.

19. Crowder, D.W.; Snyder, W.E. Eating their way to the top? Mechanisms underlying the success of invasive insect generalist predators. Biol. Invasions 2010, 12, 2857-2876.

20. Harris, R.J.; Oliver, E.H. Prey diets and polulation densities of the wasps Vespula vulgaris and V. germanica in scrubland-pasture. N. Z. J. Ecol. 1993, 17, 5-12. 
21. Barr, K.; Moller, H.; Christmas, E.; Lyver, P.; Beggs, J. Impacts of introduced common wasps (Vespula vulgaris) on experimentally placed mealworms in a New Zealand beech forest. Oecologia 1996, 105, 266-270.

22. Beggs, J.R.; Rees, J.S. Restructuring of Lepidoptera communities by introduced Vespula wasps in a New Zealand beech forest. Oecologia 1999, 119, 565-571.

23. Richter, M.R. Social wasp (Hymenoptera: Vespidae) foraging behavior. Annu. Rev. Entomol. 2000, 45, 121-50.

24. Wilson, E.E.; Mullen, L.M.; Holway, D.A. Life history plasticity magnifies the ecological effects of a social wasp invasion. Proc. Natl. Acad. Sci. USA 2009, 106, 12809-12813.

25. Markwell, T.J.; Kelly, D.; Duncan, K.W. Competition netween honey bees (Apis mellifera) and wasps (Vespula spp.) in honeydew beech (Nothofagus solandri var. solandri) forest. N. Z. J. Ecol. 1993, 17, 85-93.

26. Beggs, J.R.; Wardle, D.A. Keystone species: Competition for honeydew among exotic and indigenous species. In Ecological Studies, Vol. 186; Allen, R.B., Lee, W.G., Eds.; Springer-Verlag: Berlin/Heidelberg, Germany, 2006; Volume 186, pp. 281-294.

27. Kenis, M.; Auger-Rozenberg, M.-A.; Roques, A.; Timms, L.; Péré, C.; Cock, M.J.W.; Settele, J.; Augustin, S.; Lopez-Vaamonde, C. Ecological effects of invasive alien insects. Biol. Invasions 2009, 11, 21-45.

28. Wardle, D.A.; Karl, B.J.; Beggs, J.R.; Yeates, G.W.; Williamson, W.M.; Bonner, K.I. Determining the impact of scale insect honeydew, and invasive wasps and rodents, on the decomposer subsystem in a New Zealand beech forest. Biol. Invasions 2009, 12, 2619-2638.

29. Dvořák, L.; Roberts, S.P.M. Key to the paper and social wasps of Central Europe (Hymenoptera: Vespidae). Acta Entomol. Musei Natl. Pragae 2006, 46, 221-244.

30. Rome, Q.; Perrard, A.; Muller, F.; Villemant, C. Monitoring and control modalities of a honeybee predator, the yellow-legged hornet Vespa velutina nigrithorax (Hymenoptera: Vespidae). Aliens Invasive Species Bull. 2011, 31, 7-15.

31. Zhang, Q.-H.; Schneidmiller, R.G.; Hoover, D.R. Essential oils and their compositions as spatial repellents for pestiferous social wasps. Pest Manag. Sci. 2012, 69, 542-552.

32. Veith, H.J.; Koeniger, N.; Maschwitz, U. 2-Methyl-3-butene-2-ol, a major component of the alarm pheromone of the hornet Vespa crabro. Naturwissenschaften 1984, 71, 328-329.

33. Heath, R.R.; Landolt, P.J. The isolation, identification and synthesis of the alarm pheromone of Vespula squamosa (Drury) (Hymenoptera: Vespidae) and associated behavior. Experientia 1988, $44,82-83$.

34. Fortunato, A.; Dani, F.R.; Sledge, M.F.; Fondelli, L.; Turillazzi, S. Alarm communication in Ropalidia social wasps. Insectes Soc. 2004, 51, 299-305.

35. Bruschini, C.; Dani, F.R.; Pieraccini, G.; Guarna, F.; Turillazzi, S. Volatiles from the venom of five species of paper wasps (Polistes dominulus, P. gallicus, P. nimphus, P. sulcifer and P. olivaceus). Toxicon 2006, 47, 812-825.

36. Ono, M.; Igarashi, T.; Ohno, E.; Sasaki, M. Unusual thermal defence by a honeybee against mass attack by hornets. Nature 1995, 377, 334-336.

37. Ikan, R.; Gottlieb, R.; Bergmann, E.D.; Ishay, J. The pheromone of the queen of the oriental hornet, Vespa orientalis. J. Insect Physiol. 1969, 15, 1709-1712. 
38. Ruther, J.; Sieben, S.; Schricker, B. Role of cuticular lipids in nestmate recognition of the European hornet Vespa crabro L. (Hymenoptera: Vespidae). Insectes Soc. 1998, 45, 169-179.

39. Ruther, J.; Sieben, S.; Schricker, B. Nestmate recognition in social wasps: Manipulation of hydrocarbon profiles induces aggression in the European hornet. Naturwissenschaften 2002, 89, 111-114.

40. Steinmetz, I.; Sieben, S.; Schmolz, E. Chemical trails used for orientation in nest cavities by two vespine wasps, Vespa crabro and Vespula vulgaris. Insectes Soc. 2002, 49, 354-356.

41. Steinmetz, I.; Schmolz, E.; Ruther, J. Cuticular lipids as trail pheromone in a social wasp. Proc. $R$. Soc. Biol. Sci. 2003, 270, 385-391.

42. Ono, M.; Sasaki, M. Sex pheromones and their cross-activities in six Japanese sympatric species of the genus Vespa. Insectes Soc. 1987, 34, 252-260.

43. Spiewok, S.; Schmolz, E.; Ruther, J. Mating system of the European hornet Vespa crabro: Male seeking strategies and evidence for the involvement of a sex pheromone. J. Chem. Ecol. 2006, 32, 2777-2788.

44. Taylor, B.J.; Schalk, D.R.; Jeanne, R.L. Yellowjackets use nest-based cues to differentially exploit higher-quality resources. Naturwissenschaften 2010, 97, 1041-1046.

45. MacKenzie, J.K.; Landolt, P.J.; Zack, R.S. Attraction to ornamental peony (Paeonia lactiflora, Paeoniaceae) by Polistes dominulus Christ (Hymenoptera: Vespidae) demonstrated using olfactometers. J. Kansas Entomol. Soc. 2006, 79, 231-238.

46. Brodmann, J.; Twele, R.; Francke, W.; Hölzler, G.; Zhang, Q.-H.; Ayasse, M. Orchids mimic green-leaf volatiles to attract prey-hunting wasps for pollination. Curr. Biol. 2008, 18, 740-744.

47. Jander, R. Olfactory learning of fruit odors in the Eastern yellow jacket, Vespula maculifrons (Hymenoptera: Vespidae). J. Insect Behav. 1998, 11, 879-888.

48. Aldrich, J.R.; Kochansky, J.P.; Sexton, J.D. Chemical attraction of the eastern yellowjacket, Vespula maculifrons (Hymenoptera: Vespidae). Experientia 1985, 41, 420-422.

49. Aldrich, J.R.; Lusby, W.R.; Kochansky, J.P. Identification of a new predaceous stink bug pheromone and its attractiveness to the eastern yellowjacket. Experientia 1986, 42, 583-585.

50. Landolt, P.J.; Heath, R.R.; Reed, H.C.; Manning, K. Pheromonal mediation of alarm in the Eastern yellowjacket (Hymenoptera: Vespidae). Fla. Entomol. 1995, 78, 101-108.

51. Weston, R.J.; Woolhouse, A.D.; Spurr, E.B.; Harris, R.J.; Suckling, D.M. Spiroacetals and other venom constituents as potential wasp attractants. J. Chem. Ecol. 1997, 23, 553-568.

52. Siegel, S. Nonparametric Statistics for the Behavioral Sciences; McGraw-Hill: New York, NY, USA, 1956; pp. 1-312.

53. Baser, K.H.C.; Buchbauer, G. Handbook of Essential Oils: Science, Technology, and Applications; CRC Press/Taylor and Francis: Boca Raton, FL, USA, 2010; p. 975.

54. Cook, S.M.; Khan, Z.R.; Picket, J.A. The use of push-pull strategies in Integrated Pest Management. Annu. Rev. Entomol. 2007, 52, 375-400.

(C) 2014 by the authors; licensee MDPI, Basel, Switzerland. This article is an open access article distributed under the terms and conditions of the Creative Commons Attribution license (http://creativecommons.org/licenses/by/3.0/). 